\title{
Costumbres religiosas de los judíos melillenses
}

Jesús F. Salafranca Ortega

En principio pudiera parecer un despropósito el título de este artículo, pues induce a pensar o creer que los judíos de Melilla tienen unas costumbres religiosas propias y no siguen el rito litúrgico sefardr, común a todas las comunidades judías del Mediterráneo. Nada más lejos de nucstro ánimo y de nuestro propósito. Evidentamente los hebreos de Melilla practican como sefardíes que son el rito sefardí, pero su propio desenvolvimiento como comunidad en el marco específico de la sociedad melillense y en contacto directo con cristianos y musulmanes ha hecho que su vida religiosa tenga un matiz propio y se hayan agregado costumbres sociales practicadas específicamente en Mclilla.

En consecuencia hemos decidido realizar un pequeño resumen de la vida religiosa judía con sus fiestas y solemnidades, agregándole las costumbres sociales que tales actos litúrgicos llevan aparejados.

Nuestro estudio lo hemos fijado en los primeros treinta años del presente siglo, razón por la cual para describir las costumbres religoso-sociales de la comunidad judía de Melilla hemos recurrido al magnífico e insustituible manantial de historia local que es el diario "El Telegrama del Rif" sin cl que hubicse sido imposible redactar este trabajo, cl cual aparecerá en adclante siempre citado con las iniciales T.R.

\section{La doctrina}

La doctrina del pueblo de Isracl sc halla contenida en el Jumash (Bíblia) dividida en tres partes:

a) Ley de Moisés, o Pentateuco; Génesis, Exodo, Levítico, Números, y Deuteronomio. Denominado Torah = doctrina.

b) Los libros de los profetas. Llamados Nébiim.

c) Los libros hagiográficos. Denominados Ketubim.

Además de estos libros se admitc la tradición oral o Misná recopilada por el rabino Yehuda Ha-nasi (200 d J.C.). La Misná fue comentada en las escuelas rabínicas de Babilonia y Palestina. Estos comentarios se llamaron Guemerá. La Misná unida a la Guemerá dió lugar al Talmud (literalmente estudio), cuya redacción definitiva se llevó a cabo en Babilonia a finalcs del siglo $\mathrm{V}$.

Sin embargo, el clasificador de la doctrina judía fue Maimonides (Moshe Ybn Maymon) filosofo, médico y uno de los principales té́logos talmúdicos. Nació en 
Córdoba en 1135 y falleció en Al-Fustat (Egiplo) en 1204. Entre los hebreos es conocido por el nombre acróstico de Rambam ${ }^{1}$.

Escribio entre otras las siguientes obras: Libro de Elucidación; Repetición de la Ley o Mano fuerte; y el Libro de los Preceptos.

Este último libro es una relación ordenada y razonada de los seiscientos trece preceptos bíblicos. Dividió además la fe judáica en trece artículos, que pucden ser a su vez condensados en la profesión de fe judáica, que es como dice Caro ${ }^{2}$ el grito de batalla de la religión judía: Shemá Isracl, Adonay Elohenu, Adonay Ejad = Escucha Israel, el Señor nucstro Dios, el Scñor es Uno. Que es por tanto la afirmación rotunda y fundamental del Monoteísmo. Los puntos fundamentales de la doctrina judía son los siguientes:

- La esencia divina no se puede comprender.

- Los atributos morales de Dios son: Santidad, amor, bondad, justicia, clemencia y longanimidad.

- Dios ha creado cl mundo por bondad.

- La caridad no puede por sí sola asegurar la ordenación de la sociedad humana, por lo que hace falta la justicia.

- La humanidad constituye una gran familia salida toda ella de un mismo tronco. Por ello es necesario la solidaridad humana.

- Espiritualmente el hombre es imagen de Dios, tiene libre albedrío, aunque se le ordena que haga sicmpre cl bicn. Si falta a sus obligaciones morales puede alcanzar el perdón divino mediante el arrepentimiento sinccro, la reparación del mal causado y el mejoramicnto de la conducta.

- La recompensa y el castigo de las acciones humanas tienen lugar en esta vida terrenal y en la espiritual que seguirá a la muerte.

- Al final de los tiempos, la humanidad conocerá una feliz era mesiánica. El Mesías descendiente de David no será un ser divino sino un hombre sobre el cual reposará el espíritu de Dios. Los hombres vivirán entonces en concordia, unidos por la creencia en el Dios Unico.

- Cualquier hombre de cualquier confesión o doctrina se salvará si observan los 7 preceptos dados por Dios a Noé y a sus descendientes, preceptos en los que están comprendidos el rechazo a la idolatría y la abstención de la inmoralidad.

- El hombre tiene obligaciones para con Dios y para con los hombres. Pues el judaismo se presenta como una Alienza entre Dios y los Patriarcas y su potestad. Por parte de Dios consiste en Promesa de protección perpetua. Y por parte de los hombres en un compendio de fidclidad a Dios y a su Ley.

- Los deberes para con Dios pueden resumirse en estos dos textos de la Torah: "Amarás al Eterno, Dios tuyo, con todo su corazón, toda tu alma y todas las

(1) Fue tal la importancia de Moisćs Maimonides que un proverbio judío dice: "De Moisés a Moisćs (Maimonides) no hubo otro Moisés".

(2) Josć Caro; Shuljan Aruj: Sigal. Buenos Aires, 1968, p. 41. 
fucrzas" y "Scd santos, porque Yo, el Etcmo, vuestro Dios, soy Santo". De ahí las leyes de purcza, la circuncisión y las prescripciones relativas a los alimentos (Khaser).

- Los deberes hacia los hombres los define la Torah así:

"Amarás a tu prójimo como a tí mismo", entendiendo por prójimo hasta el no judío. De ahí las numerosas prescripciones sociales referentes a la caridad.

- Los mandamientos más importantes se hallan promulgados en el Decálogo

I. Yo soy el Eterno, tu Dios, que te ha sacado de la tierra de Egipto, de la casa se la servidumbre.

II. No tendrás otro Dios que a mí. No te fabricarás ningún ídolo.

III. No proficras en vano el nombre del Etcrno, tu Dios.

IV. Acuérdate del día del sábado para santificarlo. Seis días trabajarás y harás toda tu faena; más el séptimo día cs Sabbath = descanso, en honor del Eterno, tu Dios.

V. Honra a tu padre y a tu madre para que se prolonguen tus días sobre el suclo que el Eterno, tu Dios te dá.

VI. No matarás.

VII. No adulterarás.

VIII. NO robarás.

IX. No depondrás contra tu prójimo testimonios falsos.

$X$. No desearás adueñarte de cosa alguna de cuanto a tu prójimo pertenece.

$\mathrm{Y}$ éstas pueden ser, en breve síntesis, los puntos doctrinales fundamentales del judaísmo ${ }^{4}$.

\section{Los períodos sagrados}

Antes de proceder a adentramos en el estudio del sábado, de los días festivos, o de cualquier otra circunstancia de tipo religiosa, convicne que tengamos presente el calendario hebreo y las fiestas israclitas. Como existen variaciones respecto al calendario gregoriano vamos a reproducir dos: el de 1927 y el de 1985-1986, para que se pueda observar la difcrencia.

(3) Los hemos reproducido para que se observen las diferencias de texto con los mandamientos cristianos.

(4) Para la redacción de este aparado nos hemos servido de las siguientes obras: José Caro, Shuljan Aruj. Sigal, B. Aires 1968; Carlos del Valle. El mundo judio. UNED. Madrid 1976; Flerman Wonk. Este es mi Dios. Plaza Janés Barcelona 1967; Antología del Talmud, Plaza y Janes. Barcelona 1982; y, la Santa Biblia. Planeta, Barcelona 1964. 


\begin{tabular}{|l|l|l|l|}
\multicolumn{5}{c|}{ ANOS } \\
\hline 5688 & $1927-28$ & 5746 & $1985-86$ \\
& & & \\
Tishre & 27 sept. & Tishre & 16 sept. \\
Hisvan & 26 octub. & Hisvan & 16 octu. \\
Kislev & 25 noviem. & Kislev & 14 novi. \\
Tebach & 24 diciem. & Tebach & 13 diciem. \\
Shevat & 23 enero & Shevat & 11 enero \\
Adar & 21 febrero & Adar 1 y 2 & 10 febr. \\
Nisan & 22 marzo & Nisan & 10 abril \\
Iyar & 20 abril & Iyar & 10 mayo \\
Sivan & 20 mayo & Sivan & 9 junio \\
Tamuz & 18 junio & Tamuz & 8 julio \\
AV & 18 julio & Tamuz & 8 agosto \\
Elul & 17 agosto & Elul & 4 sept. \\
\hline
\end{tabular}

Lógicamente las fiestas fluctúan de un año a otro, pero para nuestro estudio apenas tiene importancia. Siguiendo a Caro las festividades judías se dividen en tres clases:
a) Festividades de Peregrinaje:
- Shavuot (de las semanas)
- Sucot (de las cabañas)
b) Grandes solemnidades:
- Rosh Hashaná (Año Nuevo)
- Yom Kipur (Expiación)
- Hanuca
- Purim
c) Festividades menores:
- Rosh Jodesh (Luna Nueva)
- Hilula de los Rabinim ${ }^{6}$

- Pesah (Pascua)

En la fiesta de Pesah o Pascua de los Azimos se conmemora la salida de Egipto, el paso del Mar Rojo y peregrinación por el desicrto hasta su llegada a la tierra prometida.

Durante los 8 días de Pascua se recuerdan las penalidades y privaciones sufridas. Comienza en la víspera del décimo quinto día y termina cl vigésimo segundo día del

(5) En este año existen 2 meses Adar - tengamos en cuenta que es un calendario lunar-: Adar 1, que va de 10 de febrero al 11 de marzo; y, Adar 2, del 12 de marzo al 9 de abril.

(6) Esta festividad de Hilulá no es de Caro, pues es específica de Magreb y por ende se celcbraba también en Ceuta y Melilla. 
mes de Nisan. De esos ochos días los dos primeros y los dos últimos son sagrados, no permitiéndose ningún trabajo manual, las casas de los hebreos son objeto de una escrupulosa limpieza para librarla de toda sustancia que pueda ser fermentada. Se come el célebre Matsá o pan sin levadura. En Melilla se le llamaba vulgarmente Pascua del Cordero, de la Galleta o fiesta de las mesas, por el banquete final que cerraba dicha fiesta.

¿Cómo se celebraba en Melilla la Pesah? Dejemos que sea un periodista que la vivio "in situ" quien nos lo narre:

"La Pascua israelita. Las tradicionales Mesas.

Después de ocho días terminó anteanoche la Pascua israelita con la celebración de la tradicional fiesta de las Mesas.

En pasados tiempos, la población cristiana tomaba parte en ella, invitada galantemente por los hebreos acomodados, pero poco a poco conforme, fue creciendo la población y dispersándose las familias hebreas, ha caído en desuso dicha costumbre y hoy se celebra en la mayor intimidad.

También pudimos apreciar que la fiesta israelita, si no en carácter, ha perdido algo de su animación de antaño, pareciéndose haber iniciado en ella un periodo de visible decadencia como sucede también con las demás fiestas propias de los cristianos.

Indudablemente el poder de las tradiciones se va debilitando, en señal quizás de una próxima fusión de las costumbres universales, o de una venidera convivencia o amalgama de los usos que antes caracterizaban de modo especialísimo a las distintas razas.

Nosotros para informar debidamente a los lectores, hubimos de visitar los distintos barrios, encontrando en todas partes la más franca y cariñosa acogida.

En dicha noche las familias hebreas van de casa en casa visitando sus amistades y muchas veces la luz del alba sorprende a los corteses visitantes.

Antaño como la colonia hebrea vivía en la Plaza y en el Mantelete, las calles de estos barrios se veian muy animadas; ahora habitan muchas de aquellas familias fuera de murallas y ello hace que no se lleven tan a rigor los deberes de cortesía o que se realicen durante la tarde de dicho dia. El continuo y simultáneo visiteo conduce a veces a no encontrar a los dueños de la casa, pero siempre se halla en ella próximos parientes encargados de obsequiar a las personas amigas.

Las fiestas tienen distinto carácter, aunque en el fondo sea el mismo, según la categoría social de los que la celebran. Las familias hebreas acomodadas, se sustraen algo a la tradición, pero las clases populares que habitan en algunas calles del Barrio del Poligono y en el nuevo barrio israelita, observan escrupulosamente las costumbres y usos mosaicos.

La clásica mesa varía también según los recursos de las familias, pero en ningún hogar faltan las flores, pequeño o monumental ramo deflores, la harina, la levadura, la manteca, los huevos, las espigas de trigo, las habas, las lechugas y el pescado fresco; en unas casas colocado ello en preciosos platos y artísticas fuentes; en otras, 
sobre modesta loza y barata, simbolizando todo cllo el trabajo y la fecundidad de la tierra y del mar, como tinico y naturales propulsores de la riqueza humana.

En torno a las mesas, las familias en fervorosa oración dan gracias al Altísimo, e impetran de él mayor holgura y bienestar para el próximo año.

En unas, abundan las jaleas, los almíbares, las compotas, las frutas enmeladas, los licores cargados de olorosas esencias, la gran fuerza alcohólica, todo ello confeccionado en casa por manos femeninas, que preparan dias antes, como nuestras abuelas las confituras de Navidad.

En otras se advierte menos variedad y son también menos gratos los almibares $y$ de menor precio los licores. En unas iluminan las mesas con preciosas lámparas eléctricas, en otras, modestas velas, sobre candeleros de bronce. Pero cada cual, según sus recursos, el rico en el esplendor de su riqueza y el pobre en las estrecheces de su pobreza, procuran festejos dignamente el término de la solemne Pascua, para reanudar al dia siguiente sus repectivos trabajos.

Decimos que los israelitas pudientes son menos apegados al rigor de las costumbres tradicionales. Y con efecto, penetrando en la casa de los Salama, Melul, Benarroch, Hassan, Charvit, Sicsu, Cohen, Benhamon, Cresciente, Botebol, Serfaty, Cattan y otros privilegiados de la fortuna, se admiran en sus viviendas, riquezas, suntuosidades, refinamiento de gusto y gran confort.

Las damas visten elegante "toilettes" a la europea, batas de seda finisimos encajes y de irreprochable corte, "ledernier cri" de la moda. Lo que más cautiva en dichas moradas es la espléndida y natural belleza de sus dueñas, que bastaria para reclamar la de la mujer semita, si no fuese ya tradicional.

Se organizan veladas cultas como en nuestra sociedad; se hace música, se rinde culto al "bell canto" pues entre dichas damas y señoritas, las hay que son verdaderas artistas; como la encantadora Sol Salama, la bellisima gibraltareña, esposa de don David S. Melul, la hermosa señora de Hassan (don Jacobo) y muchas más que escapan a la memoria de los cronistas.

En otras casas, como en la de David Charvit, acompañaban a su moradores señoras y señoritas cristianas amigas intimas de aquellas, como las simpáticas señoritas de Moreno y bella señora de Barrechina.

Aquellas tocando el piano y ésta cantando magistralmente inspiradas coplas de Andalucía y Aragón, proporcionaron momentos de verdadero solaz rindiendo culto al arte, para el cual no existen distinciones, porque es el idioma del sentimiento y por lo tanto universal. Las jovencitas hebreas, acostumbran también disfrazarse. Vimos a una hija del Sr. Charvit vistiendo un rico traje de mora argelina. Repetimos que las fiestas pascuales israelitas y en especial las de la última noche con la celebración de la mesa, se conservan más puras, tipicas y originales entre los hebreos del Polígono. En una de dichas casas, habitada por Abraham Ben-liti, notamos un ambiente de franco españolismo, vimos en la cabecera de la cama un cuadro con un retrato de los Reyes de España.

Los cronistas visitantes anteanoche de algunas casas israelitas nos preguntába- 
mos ¿cómo viven en el retraimiento tantas mujeres hebreas hermosas y elegantes sin frecuentar los paseos y teatros? Dificilmente podíamos dar a nuestra pregunta una contestación que nos satisfaciera.

No será sin duda porque la intransigencia religiosa las aleja de nuestra sociedad, pues en Melilla, más que en ninguna parte, se da a todas horas evidente muestra del respeto que mutuamente se deben guardar todas las creencias.

Y no hallando motivo justificado para dicho aislamiento, es preciso que las bellas damas y señoritas hebreas salgan de él rompiendo la clausura en que viven.

No dariamos cumplimiento a un deber de obligada gratitud, si los que suscribren no reiteran ese sentimiento públicamente a cualquier familia, distinguidas las unas y modestas las otras, hicieron anteanoche a éstos cronistas de la fiesta hebrea, objeto de toda clase de honores y distinciones" ?.

Shavuo o Fiesta de las Semanas, se celebra el sexto y el séptimo día del mes de Sivan. Fiesta de agricultores, festeja el fin de las siete semanas de cosecha del cereal. También se conmemora el comienzo de la vida espiritual de Israel, ya que fue la época del año que los judíos recibieron la Ley en el Monte Sinar. Es una fiesta sinagogal y de carácter simbólico leche y miel en la mesa y su vestigio externo se manifiesta en adornar la casa y la sinagoga con plantas y flores, pero sin relevancia social distintiva.

El Sucot o Fiesta de las Cabañas comienza con el décimo quinto día y termina con el vigésimo tercer día del mes de Tishre. La razón de esta fiesta está expuesta de forma meridiana en la Biblia: "A los quince días de este mes séptimo será la solemnidad de las cabañas para el Señor por siete días"8. "En cabañas habitareis siete días. Para que sepan vuestros descendientes que en cabañas hice yo habitar a los hijos de Israel, cuando los saqué de la tierra de Egipto" . En estas fechas en las azoteas o patios de los israelitas de Melilla se construía con cañas de Sucá (cabaña) en la que participaban alegremente -en especial los niños-todos los miembros de la familia, la cual dentro de las posibilidades económicas era embellecida con adornos y tapices. Durante esos siete días la actividad fundamental de la familia se desarrollará en la sucá, como por ejemplo: comer, beber, estudiar, divertirse y dormir. El último día festivo es el Simhath Tora (Regocijo con la Ley), concluye con él la lectura de los capítulos finales de la Torá y vuelve a comenzarse por el Génesis. La fiesta de la Cabaña era y es la festividad judía, conjuntamente con Purim, más visible de Melilla, pues se distinguen fácilmente las cabañas en las azoteas y patios y los cánticos y charlas que salen de ellas durante las noches ${ }^{10}$.

Dos son las grandes solemnidades litúrgicas y van muy seguidas en el calendario hebreo: Rosh Hashaná y Yom Kipur. Comencemos por la primera. Rosh Hashaná significa Día del Año Nuevo, y se denomina también Yom Tervá, día o fiesta de la

(7) T.R., 15-4-1909, n 1924.

(8) Levítico $23,34$.

(9) Levítico 23, 42-43.

(10) Algunos judios pudientes los dejan instalados permanentemente - $\sin$ ajuar- durante todo el año en sus azoteas. 
trompeta ${ }^{11}$ o Yom Hazikaron, Día del Recuerdo. Anuncia para cl judío un período de penitencia y está consagrado a la oración y al pensamicnto scrio. Es cclcbrada el primer y segundo día del mes Tishri. En esta festividad todo judío debe observar su conducta durante el año que pasó, debe decidir comenzar una nueva y más santa vida y debe renovar su confianza en Dios.

Los diez días de arrepentimiento, desde el primer día de Rosh Hashaná hasta cl final del Yom Kipur, están destinados a la penitencia.

El Yom Kipur (día de la Expiación o del gran Perdón) cl décimo día cxpiación y de aflicción del alma. Se ayuna totalmente durante 30 horas y se debe perdonar de corazón a los enemigos en ese día. Es un día por tanto de auto-introspección en el que se solicita perdón por los pecados al Altísimo. Ambas festividades se distinguen facilmente pucs los comercios israelitas están cerrados, las sinagogas llenas y el silencio es la tónica general en las casas judías. Como novedad cabe destacar que en las sinagogas de Melilla se introdujo la costumbre que antes de empezar los oficios del Kipur se hicieran votos por la vida y prosperidad del rey Alfonso XIII. Durante la República se suspendió esta piadosa costumbre que volvió a renacer años después de la Guerra Civil, rogándose por la vida y prosperidad de Francisco Franco. Igualmente, desde el curso académico 1988-89, cl Calendario Escolar melillense, considera a todos los efectos, festivo el Yom Kipur.

Dentro de las festividades menores y en el día 25 del mes de Kislev se conmemora Hanuca o Fiesta de las luces, por la libertad del templo de Jerusalem, conquistada por la espada victoriosa del héroe Judas Macabeo. Durante ocho días los hebreos encienden unos candiles de aceite de oliva, uno cada día, hasta llegar a ocho. Ficsta familiar sin trascendencia social alguna.

Se denomina Rosh Jodesh (Luna Nueva) a la fiesta de consagración de la luna que debe hacerse cuando han transcurrido por lo menos tres días de la luna nucva y no más de catorce días plenos, 18 horas, y 22 minutos. Debe realizarse al airc librc. Normalmente se hacía en Mclilla cn las azotcas. La tradición ha convertido esta celebración en una ficsta para mujeres, pues estas se abstienen de trabajar este día y se nota su gozosa presencia en patios, corrillos o pascos.

La fiesta más visible bajo cl punto de vista social cs la del Purim, que se celcbra el décimo cuarto día del mes de Adar y conmemora la salvación de los judíos de Persia de la aniquilación tramada contra ellos por Aman, primer ministro del rey de Persia: "Purim significa suerte, y se refiere a las suertes hechadas por orden de Aman para decidir en qué día serían exterminados los judíos de Persia. Las suertes fueron vueltas contra Aman por Esther, la reina, y su pariente Mardoqueo, y el día se transformó en un día de victoria y gozo para los judfos y de infortunio para sus enemigos"12.

Esta es la fiesta en la que más tinta ha gastado "El Telegrama del Rif" en describirla y es raro el año que pasaba sin escribir algo sobre ella. Nosotros hemos

(11) Antiguamente y en el actual estado de Isracl el sonido se hace con un Shojar (cuerno de camero).

(12) Caro, Op.cit. pág. 195. 
elegido un artículo que nos parece que expresa mejor el Purim melillense - llamado también carnaval judío - y su entomo sociológico y mental:

"Desde el primer día de la luna de Adar empiezan a trasnochar ocupándose en cantar y tocar instrumentos. Los Rabinos les exhortan a que prosigan estos dias los pleitos que tengan pendientes con los enemigos, en razón en que el planeta que rige es muy poderoso en favor suyo. (Esto no lo creen asi los cultos hebreos de Melilla). En este dia tienen licencia para empinar el codo, y comer demasiado, no siendo extraño que la presión alcohólica perturbe el cerebro, dando lugar a algún desaguisado que no pueda evitar el planeta, a pesar de subuena intención en favor del pueblo hebreo.

El día 13 de la citada luna de Adar suelen ayunar en memoria del ayuno que hizo Esther y Mardocheo recomendado al hebreísmo.

Por la tarde van a la Sinagoga y un cantor entona en voz alta toda la historia de Esther, según está en el texto de nuestra sagrada Escritura y cuando llega a pronunciar los nombres de los hijos de Amán, patean, hacen gran estrépito en el suelo $y$ bancos con toda suerte de instrumentos que tienen a mano, o con los bastones, $y$ al fin de la fiesta dicen:

"Maldito sea Amán, sea bendita Esther, malditos los cautivos; sean benditos los hebreos".

Al ver esto los circunstantes, hacen ruido como se dijo antes, y los niños rompen ollas o vasijas de barro en señal de alegría.

Terminada la fiesta de la Sinagoga, van a sus casas y leen dicha historia a sus familias, para luego sentarse a la mesa para comer más de lo ordinario, así como beber según el mandato rabino.

En la mañana del día siguiente vuelven a la Sinagoga para leer nuevamente la historia de Esther; y es costumbre en este día regalar objetos o dinero, los padres a los hijos, los amos a los criados, los discípulos a los maestros y lo pasan todo en cánticos, juegos o comidas, y hasta vistiendo de máscaras en muchas localidades.

Mandan los Rabinos que en este dia se envien mutuamente los hebreos regalos $y$ presentes, y que si alguno por ser pobre no pudiese verificarlo, cambie con otros su cena; lo que se observa muy poco.

Dispénseme los hebreos si digo es digno la censura y abominación y en lo cual demuestran sus sabios gran falta de sentido comin, y un ataque directo a la moral, al ordenarles que en esta tarde preparen una opipara cena; y en ella deban por obligación embriagarse de tal modo que el entendimiento quede adormecido y no sea capaz el uso de la razón y si alguien lo dudase lea en el Tahmud, tratado Meghilah, capítulo $1^{\circ}$, página 7 , estas palabras:

'El hombre está obligado a emborracharse en el Purim, de tal suerte que no haciendo a discurrir entre el maldecido Amán y el bendecido Mardocheo y Mardoqueo'.

$Y$ por si no se entendiera bien, Eabbi Salomé, dice:

'Embriagarse con vino'. 
Pero no indica si la cosa es saludable y si obligatoria.

Doctrina puramente rabinica y tan contraria a la razón, parece no debia hallar gran eco; no obstante, el que haya visitado dicha tarde ciertas juderías apartadas de los centros de cultura hallará en muchos delirantes y borrachos, obedeciendo el mandato de falsos y malos maestros.

Esto no lo veréis por la cultura de los hebreos que en ella moran, que si bien obedecen el mandato, es con cierta mesura; fuera de determinadas clases sociales, a los que no alcanzan los consejos de los hebreos cultos y liberados cual son la mayoria de los que moran en esta plaza" ${ }^{13}$.

Pero además había una faceta del Purim en la que también participanban gozosos cristianos y musulmanes, bien en casas particulares, en los dos casinos de la ciudad o en la calle: el juego, especialmente el bacarrat y "por severo que fuese el Comandante General y rigurosa la orden prohibitiva del juego, se autorizaban los tres días del Purim, y la mesa del bacarrat funcionaba día y noche"14. Algunos - cristianos, judíos o musulmanes- lo continuaban por su cuenta y dieron por ello, con sus huesos en el calabozo por lo menos durante un par de días.

Hilula se puede traducir por conmemoración de difuntos y Hilula de los Rabinos por conmemoración de los rabinos difuntos, naturalmente de aquellos rabinos que habían llevado una ejemplary santificante vida. Pcro dejemos que una vez más sea "El Telegrama del Rif' quien nos lo cucnte:

"Fiesta israelita". Conmemoración de difuntos.

El jueves de la próxima semana tendrá lugar la fiesta isráelita llamada 'HilLula', en la cual conmemoran a los difuntos que han alcanzado en ellos fama de santidad.

Son muchos los lugares de Marruecos donde hay Rabinos de fama universal dentro de la religión mosaica.

Uno de los más famosos del Norte de Africa, es sin duda alguna el del cementerio hebreo de Tlemcen (Argelia).

Anualmente concurren a él desde puntos muly lejanos, incluso de América, muchas familias que pasan la noche en el cementerio celebrando una fiesta a la que llaman 'Sooda'.

Este año promete verse muy concurrida Tlemcen, pués ayer comenzó el embarque de israelitas en Melilla, a bordo del vapor 'Ciudad Soller'.

No ha de ser éste el único buque que conduzca alli a estos viajeros, sino que todos los que vayan saliendo esta semana irán israelitas. Aqui en Melilla, en el poblado de Messamer de la kábila de Mazuza, se encuentra enterrado bajo una enorme piedra desde hace más de 500 años, el célebre Rabi Saadia, muy venerado entre los israelitas de esta comarca.

Como en años anteriores, el jueves próximo marcharán a Messamer a visitar esta

(13) T.R., 15-3-1903, $\mathrm{n}^{2} 367$.

(14) T.R., 25-3-1931, $\mathrm{n}^{2} 11.254$. 
tumba, muchos israelitas melillenses. Cada año, en vista de la seguridad del territorio, es mayor el nimero de los que hacen esta visita religiosa.

En esta época, el indígena dueño de la finca en que está la sepultura, recoge muy pingües limosnas de los visitantes" 15 .

Pero no sólo se celebraba el Hilula fuera de Melilla, en la propia ciudad se festejaba el del Rabbi Shimhon Bar Yohy con un amplio programa de actividades recreativas y culturales así como peregrinación de judíos procedentes de Marruecos y de Argelia:

"Hilula de Riby Shimhon.

Los días 2 y 3 del próximo mes de mayo, se verificarán diversas fiestas organizadas por la Comunidad Israelita de esta ciudad, con motivo de la celebración de la Hilula. Tendrá lugar en el Talmud Torah, celebrándose el día 2 con arreglo al siguiente programa:

A las 6 de la tarde, Meldado de la Idera zota.

Seguidamente el profesor don Jacob Chocrón y un coro de niños cantarán el Harbit. El Gran Rabino, Reverando Reby, David Salomón Cohen y el Presidente de la Comunidad Israelita don Yamin A. Benarroch pronunciarán discursos.

Por último se subastarán las velas dedicadas a los Sadikin más renombrados y los ramos de flores, también dedicadas a los Rabinim y Sadikim.

Durante esta subasta, un coro de niños acompañados de su profesor, amenizará el acto con Pilluim.

Con motivo de las fiestas, el edificio del Talmud Torah y sus jardines serán iluminados y los concurrentes serán obsequiados con un lunch.

El día 3, desde las 5 de la mañana, se celebrará una gran fiesta y festival en el Sadik Reby Eldati, amenizando el acto una banda de muisica.

Los niños del coro interpretarán diversos cantos acompañados de su profesor, señor Chocrón.

El referido día tendrán lugar en el cementerio israelita, los acostumbrados actos. Se espera que para la fiesta vengan numerosos israelitas de la zona vecina y de Argelia" 16 .

Se observa fácilmente que el día de difuntos entre los israclitas no es día de luto ni de tristeza, sino todo lo contrario, festivo, concecuentemente con el principio judío de "que la muerte es la meta santa de una vida sagrada"?

Acabaremos indicando que la Hilulá del Rabbi Shimhon ha cruzado el Mar de Alborán y hoy la celebra la Comunidad Israclita de Málaga. Asimismo se ha establecido en Melilla peregrinar a la tumba del Gran Rabino Abraham Cohen ${ }^{18}$ en las fechas del Hilulá.

(15) T.R., 8-5-1914, $n^{9} 3.889$.

(16) T.R., 28-4-1934, $n^{2} 11.907$.

(17) Caro. Op. cit. pág. 264.

(18) Santo y sabio varón que fue el primer Gran Rabino de Melilla. 
Hemos dejado intencionadamente para el final y fuera del cuadro del día festivo por excelencia: el Sabbath, el sábado, el día del descanso absoluto. Tan importante es que Caro en su obra le dedica un capítulo con dieciocho apartados. Varias veces en la Biblia se menciona la obligación del descanso sabático y éste es una de ellas: "seis días se efectuará trabajo, más en el séptimo día será el descanso sabático, cosa santa en honor del Altísimo. Observaron pues los israelitas el sábado, celebrando el sábado a través de sus generaciones. Será señal perpetua entre mí y los hijos de Israel"19.

No vamos a describir, bajo el punto de vista religioso todo el ritural del sábado, sólo recordar que ese día es el eje fundamental en el que gira toda la doctrina judía y en la que se conjuga perfectamente la sociabilidad familiar del acto litúrgico judío. Como el sábado comienza en la tarde del viernes, ese día es de ajetreo para el ama de casa judía que hará limpieza general en su casa, cocinará para las tres comidas rituales, pondrá ropa limpia en las camas y en la mesa, y encenderá en su momento las velas sabáticas. Todos los miembros de la familia se lavarán a ser posible con agua caliente y vestirán sus mejores ropas. El sábado es por excelencia el día del Señor, el día del goce y de la luz, donde se comerán los mejores manjares y se beberá el mejor vino. Es fácil distinguir el Sabbat; los comercios cerrados, las oraciones en las sinagogas y las familias reunidas para la gran cena del sábado (Viernes por la noche). Por la mañana después de asistir a la sinagoga ${ }^{20}$ las familias judías melillenses, paseaban y pasean, por la Avenida luciendo sus mejores prendas en especial las mujeres que aprovechan el sábado para portar joyas y adornos.

Es día de alegría, de rezos y de entrañable unión familiar en el que se cumple, normalmente a rajatabla la orden bíblica: "No hagas en él (sábado) obra alguna"21 Caro señala treinta nucve tareas que están prohibidas en sábado y nosotros hemos tenido ocasión de observar en muchas ocasiones la estricta aplicación de la ley del descanso sabático ${ }^{22}$.

(19) Exodo 31, 15-17.

(20) Es obligatorio para todo buen judio rezar en la sinagoga tres veces al día: por la mañana: Shajarit; por la tarde, Minjá; y al anochecer Maariu. Siendo necesario que haya por lo menos, 10 varones. Minyan.

(21) Exodo 20, 10.

(22) Valgan de ejemplo estos tres casos:

1: Cuando vivíamos en Mclilla, frente a nosotros vivía una señora judía que un sábado antes de la cena ritual (viemes por la noche) se le fundió el plomillo quedándose sin luz. Nos pidió que lo arreglásemos pues ella no podía, a lo que naturalmente accedimos.

$2^{2}$ : En un viaje de cstudios con alumnos del Instituto de Mclilla a Granada, se desmayó una chica judía por no haber comido nada durante el sábado, ya que no podía tocar dinero en ese día para comprar comida. Tuvimos que comprarle melocotones, manzanas y un bocadillo de queso, pues cra tan ortodoxa que su alimemento tenía que ser Khaser.

$3^{\circledR}$ En un viaje por Isracl nos cogió un sábado en Safed, pequeña ciudad al Norte de Galilea, habitada sólo por israclícs y no pudimos cenar ni comer, pues no había ningún restaurantc abierto. Ilicimos involuntariamente un día de ayuno. 


\section{Vida religioso-familiar}

\section{a) Matrimonio}

Nos habíamos propuesto desde el principio de este capítulo hacer un pequeño resumen de los actos litúrgicos hebreos e incidir sobre todo en las reglas sociales que tales actos alcanzaban, mas en este caso vamos a saltarnos nuestra propia regla e indicaremos, que según Alvar, es Manuel L. Ortega el único autor sobre judíos sefardíes que ha descrito minuciosamente una boda hebrea, a él remitimos ${ }^{23}$ pese a que somos conscientes de la dificultad de encontrar su preciado libro, $Y$ nosostros por nuestra parte seguiremos usando y abusando de "El Telegrama del Rif" - sin el cual casi no podríamos haber realizado el presente trabajo- y dejaremos una vez más y no la última - que nos deleite e instruya hojeando en sus amarillentas páginas cómo fue una boda judía en la Melilla de principio de siglo:

"Boda judia"

Tarea dificil es abrirse paso entre la apiñada muchedumbre que invade la elegante sala de los señores de Salama. Todas las miradas están fijas en el artístico trono, en el tálamo del ritual, donde se asiente la encantadora Sol Salama, radiante belleza, con regio traje de seda liberti y finísimos encajes. Semeja visión divina, cubierta con amplio velo blanco, reclinada la cabeza, orlada de azahar, sobre ricos almohadones, cerrados sus hermosos ojos negros, como abstraida de cuanto ocurre en torno suyo.

Son las dos de la tarde cuando da comienzo la ceremonia.

El novio, que viste traje de etiqueta, echa sobre sus hombros el Talet, especie de chal de seda. El reverendo Moisés Taurel, toma en sus manos un cáliz sagrado lleno de vino, lo bendice y salmoda versículos que corean los hombres, permaneciendo todos cubiertos. De ese vino beben los novios y seguidamente él coloca en el diminuto indice de la mano derecha de ella, el anillo nupcial.

Otro rabino, el reverendo Abraham Cohen, da lectura al contrato matrimonial, escrito en caracteres hebráicos sobre pergamino orlado de figuras bíblicas.

Es un contrato a la usanza castellana, como se hace constar en el documento, tradicional observada por los descendientes de aquellos hebreos expulsados de Castilla, en él se especifican los bienes que aportan los cónyuges.

El mismo Rabino toma después otro cáliz que bendice entre salmos, bebiendo de su contenido los padres y parientes.

El matrimonio está consumado, pero cuando el bullicio y la alegría suceden al silencio que imperó durante la ceremonia, se rompe un vaso, cuyos pedazos se esparcen delante del tálamo. No es casual la rotura. Lo estrella sobre el suelo el Rabino, para recordar a los desposados que no deben envanecerles las pompas mundanas. También el pueblo de Israel fue grande y vió derrumbarse el templo

(23) Manucl Ortega "Los hebreos de Marnecos". Hispano-americana. Madrid 1919. p. 177-186. 
venerado de Jerusalem. Es un toque de atención que refrena la alegria y hace pensar en lo mudable de las cosas humanas.

La novia desciende del trono, y pasea triunfante por las casas acompañada de sus padres, rodeada por sus parientes, seguida de los salmistas que entonan alabanzas al Dios de Jehová, al Dios del Sinal, al Dios de todos los creyentes.

Las jóvenes se apresuran a despojarla del velo y guardar con unción alfileres y azahar, reliquias preciadas, amuletos que adelantarán el día de su dicha.

Las puertas de las casas permancen abiertas a los ricos y a los pobres. A nadie está vedada la entrada.

De ahi que durante la ceremonia se confundan en la sala gentes de la más opuesta condición social.

Es un templo al que todos tienen acceso.

Los criados reparten bolsas de confites, y, lentamente la sala se despeja, quedando en ella los invitados.

Entonces el cronista que atraído por la curiosidad, halló franca la entrada, recrea su vista en tanta mujer hermosa como alli hay congregada, luciendo elegantes tocados, entre los que descuella el de la dueña de la casa, de seda negra adornado con plata y los de otras muy hermosas damas que el cronista no describe por estar poco versado en modas femeninas.

En el comedor se sirve espléndido lunch, compuesto de manjares de la cocina hebráica, repartiéndose a las señoras preciosas cajas de dulces.

Hacen los honores con exquisita amabilidad los dueños, sus hijos y sus hemanos"24.

De esta hermosa ceremonia qucremos destacar tres aspectos, dos contenidos en el artículo y otro no mencionado. El primero de cllos es el contrato matrimonial o Ketubah que en contra de lo que opina el periodista no es una especificación de los bienes que aportan los cónyuges, ya que la Ketubah se puede dividir en cuatro partes: La promesa del novio a la novia de protegerla, amarla, serle fiel, etc. La dote que el novio da a la novia; La aceptación por parte del novio de la integración económica de la novia en todos los negocios y propiedades suyas; y la promesa del novio de no casarse con otra, no llevarla a otro país sin su consentimiento y a pagarle todo lo reconocido y darle acta de divorcio en caso de desavenencia.

La Ketubah por regla general, la guarda el rabino que aclúa como notario y en algunos casos pasa a la familia de la novia. En muy pocos casos hay que recurrir a ella para hacerla cumplir legal y forzosamente.

El matrimonio es el acto más solcmne y alegrc del ceremonial religioso israelita. Por la circuncisión se mantiene la alianza entre los hombres y Dios y un nuevo ser entra en el señor del judaismo. Pero el matrimonio es el pilar básico del judaismo. Sin familia judía no existiría hoy el judaismo. Es la familia donde los niños se impregnan

(24) T.R., 24-6-1909 
y viven cotidianamente la csencia de la religión judía, pues lodos los actos desde cl más simple (Levantarsc por la mañana y lavarse las manos) hasta cl más sagrado (festejar el sábado) cstá reglado por cl judaismo. La familia judf́a es cuna, cscucla y templo del pueblo de Isracl ${ }^{25}$. Pero el pueblo de Isracl ha tenido avatares, por eso en medio del bullicio y la alegría de los contrayentes, amigos y familiares por la nucva familia judía, el rabino rompe una copa de cristal llena de vino para recordar a todos los presentes que no hay gozo completo cn la vida y que en medio de las alegrías, incluso de las mayores, asoma siempre la sombra del dolor.

El último aspecto que queremos destacar es la obligatoricdad de ser de oro el anillo nupcial que el novio ofrece a la novia, el cual pregunta a los presentes si es del metal que la Ley exige. Si dos peritos dan su visto bueno se acepta la sortija y el varón la coloca en el dedo índice de la mano derecha de la desposada, diciendo que por ese anillo, según la Ley de Israel, le pertenece a partir de ahora.

\section{b) Circuncisión}

Es el acto físico por el que un niño varón de Isracl es consagrado al reino de Dios: "Os circuncidarcis, pues la carne del prepucio, lo cual vendrá ser señal de alienza entre mí y vosotros ${ }^{26} i$ En qué época? También lo explica la Torah: "Cuando cuenten ocho días se os circuncidará a todo varón en vuestras diversas generaciones" 27 . Lógicamentc si está sano y puede sufrir la opcración que realiza un $\mathrm{Mohel}$ (circuncidante) que realiza su función gratuitamentc. Un mohel no es un cirujano, ni un vulgar matarife, se necesitan estudios especiales y una gran habilidad para tal cargo. Para la circunscisión se utiliza una cuchilla pequeñita y muy afilada y un aparato de plata de forma cilíndrica. El Sandek (padrino), gencralmente el abuclo, se sienta con cl niño en brazos

(25) Caro, Op. cit. Le dedica un capílulo con veintitres apartados. Nosotros hemos encontrado un decálogo de la familia judía:

$1^{2}$ - Ahava Isracl - Ama a tu scmejante como a tí mismo.

$2^{2}$ - Jinuj. Asegura una autćntica adecuación scgún la Torah para tus propios hijos y para cada nino y niña judíos.

$3^{2}$ - Torah. Estudia Torah cada día y cada noche.

$4^{2}$ - Mezuza. Fija una Mezuza en el marco derccho de la puerta de cada habitación.

$5^{9}$ - Tzcolaka. Ejerce la caridad cada día hábil (excepto sábados y ficstas judías).

$6^{9}$ - Telifin Los varones mayores de 13 años deben colocarse tefilin cada día hábil (excepto sábados y fiestas judías).

$7^{2}$ - Bait Male Isfarim. Todo hogar judío debe tencr libros sagrados judíos, por lo menos un Jumash (Biblia), un Sidur (Libro de oraciones) y un Tchilim (Salmos).

$8^{2}$ - Ner Shel Shabat Kodesh. Las mujercs, incluyendo las niñas desde los tres años deben encender las velas cada día del sábado y Yom Tov, a la debida hora y recitar las respectivas bendiciones.

$9^{2}$ - Kashrut. Se debe comer Kasher en cl hogar y fuera de él.

$10^{\circ}$ - Taharat-Harnishpaja. Para tener una familia feliz, sana y unidad hay que mantener la tradición de la pureza familiar (matrimonios entre judíos).

(26) Gćnesis 17,11

Hoja sinagogal repartida con molivo del Purim de 5743 1983, en la Comunidad Israclita de Madrid.

(27) Génesis $17{ }_{12}$ ' 
y el mohel y los dos concurrentes - sólo varones que sean considerados hombres rectos- permanecen de pie mientras que se celebra la circuncisión que debe ser instantánea y rezar y zantar oraciones especiales para el caso ${ }^{28}$ imponiéndosele en dicho acto el nombre que ha sido elegido de antemano por la familia del padre o de la madre ${ }^{29}$.

Después del acto se celebra un festcjo muy parecido a los bautizos de cristianos. Los familiares, amigos y convecinos, sean o no judíos, son invitados a un ágape donde se sirven licores, comida y dulces y en casas acomodadas se da hasta baile. Es costumbre que el niño sea ofrecido a los invitados, los cuales le hacen regalos normalmente en metálico.

Respecto a las niñas se ha popularizado la costumbre social — no religiosa — de realizar una ceremonia llamada de imposición de nombre, que en su aspecto social no presenta variante respecto a los varones, es decir, ágape, bailes y regalos.

\section{C) Defunciones}

Según el judaísmo la vida es sagrada "y no debe ser gastada meramente en placeres corporales, sino debe ser consagrada principalmente a la ejecución del Todopoderoso. La muerte, dentro de esta concepción, es realmente la meta final de la vida, en la que el alma, libre de su envoltura material, se toma pura y sagrada, remontándose su origen". Para poncr en evidencia que la muerte es la meta santa de una vida sagrada, el judaísmo desde tiempos inmemoriales, sentó numerosas reglas legales referentes a las personas moribundas, al trato de los muertos y al luto. Es el deber sagrado de todo judío interiorizarse de esas $1 \operatorname{cycs}^{30} \mathrm{El}$ trato a los moribundos y difuntos se rige por el Seder Tahará (Rito de difuntos) ${ }^{31}$ y el deber de realizarlo se canaliza a través de la Hebrá Guemilut Hasadim.

En Melilla cuando un enfermo entra en período agónico se llama a los mienbros de la Hebrá, uno de los cuales - del mismo sexo del cnfermo- recitará las oraciones pertinentes y estará en todo momento con cl moribundo, pucs nadie debe morir en soledad, sin tocarlo, para no acclerar aunque sea indirectamente su mucrte. Cuando ha ocurrido el bbito se notifica al oficiante.

El cuerpo del difunto se deja como está durante un intervalo de diez minutos, después se le cicran los ojos, con la barbilla hacia arriba, para mantener la boca el

(28) Jesta ccremonia nos la describió lacónicamente Jacob Almosnino, Mohcl de Melilla, en la época de redacción de este artículo, año 1986.

(29) El primer hijo "penenece" a la familia del padre, el segundo a la de la madre y así sucesivamente.

(30) Caro, Op. cit., p. 263-64.

(31) La Tahará que se realiza en Melijla se hace conforme a un Seder Tahará publicado por la Congregación Shearit Isracl de Nueva York. S/F. Traducido al español y ordenado por Jacob Bentata en colaboración de Víctor Tarry. Supervisado por el Reverendo Hajam Salomón Gaón. Gran Rabino de las Comunidades Sefardíes de Gran Bretaña y de la Conmonwealth. Debemos su posesión a un amable regalo de nuestro apreciado amigo Lcón Benguigui Cohen. 
cuerpo durante una hora. Pasado cl ticmpo se cubre cl cuerpo con una síbana; se coloca una bujía encendida a la cabecera y otra a los pies. Si la mucrte ocurre en sábado, cl cadáver permanecerá en la cama hasta terminar el sábado.

Los restos no se dejan solos. Siempre hay un velador - mienbro de la Hebrádel mismo sexo del difunto, que de día o de noche lee literatura devocional. Hay que enterrarlo por consideraciones higiénicas y por costumbre inmemorial judía antes de los tres días ${ }^{32}$. Cuando por necesidades médicas o policiales no se ha podido sepultar se preserva el cadáver con hiclo. Aunque vedados por la Ley judía, el embalsamamiento y la autopsia, sólo se autorizan por fuerza mayor o por imposición judicial.

El cadáver ha de ser preparado para el entierro con la propiamente dicha Tahará (purificación, lavado, limpieza) ${ }^{33}$ Esta función por ser sagrada se celcbra en silencio y devoción. Durante todo ella el cuerpo permanece cubierto por una sábana.

La Hebrá manda a la casa del difunto la tabla de Tahará, que previo lavado, se coloca sobre ella al difunto con una sábana. La Tahará la realizan dos o más hermanos de la Hebrá, nunca uno solo y siempre del mismo sexo del fallecido. Luego se levanta la tabla hasta su posición, con los pics del difunto hacia la pucrta y mediante rezos y oraciones funerarias proceden a lavarle todas las partes del cuerpo con un complicado ritual, vistiéndole a continuación con prendas blancas de lino, algodón o lana, en recuerdo de los antiguos sacerdotes que vestían de lino blanco en presencia de Dios. Se le viste por tanto con sencillcz, sin adornos ni ornamentos, a los hombres se les coloca el Talit, después de romper uno de los nudos de las fimias y se les coloca en el ataud en posición de reposo cubrićndolo con un paño negro.

Al traslado del cadáver acuden familiares y amigos - estos últimos judíos, cristianos o musulmanes - y a la llegada al cementerio se deposita el ataud en una salita dispuesta al cfecto, los hombres se quedan en cl patio y las mujeres - de la familia o conocidos-en una sala adjunta y contigua a la que se dejo el catafalco.

Llevando a su frente al rabino y rezando plegarias funerarias, sólo los hombres acompañan al cadáver y delante de una fosa antropomorfica excavada en la tierra lo depositan sin caja, envuclto en su sudario. Se hecha tierra en la tumba y es cerrada por un armazón de ccmento, que más tarde - depende de la categoría social de la familia - será recubierto con marmol y en la lápida, normalmente en hebreo, ponen el nombre del difunto y fecha de nacimiento y defunción. Acto seguido se le da una vez más el pésame a los familiares, se depositan unas monedas para los enterradores, se lavan ritualmente las manos y se despide el duelo.

Las leyes del luto, que las cumplen los judíos melillenses a rajatabla, se dividen en tres partes: Shivá $=$ siete días; Shloshim $=$ treinta días y Rosh $=$ año.

(32) En Melilla usualmente antes de las veinticuatro horas, en el Cementerı específico de la Comunidad judía, aledaño del cristiano de la Purísima Concepción, que sustituyó, desde 1893, al de San Carlos.

(33) Indica el Seder Tahará: "Ninguna Tahará es pemitida cuando los que toman parte de ella se exponen a algún peligro. Así, los que mueren por difteria, virucla, fiebrc tifoidea u otras enfermedades contagiosas o infecciosas, han de ser colocados en ataud precintado y llevados al cementerio con el menor retraso posible", p. 2. 
Durante el Shivá a los familiares más íntimos les está prohibido practicamente todo, salvo las labores domćsticas, por ejemplo: cumplir trabajo alguno, bañarse, untarse, darse masajes, llevar calzado de cuero, mantener relaciones sexuales, estudiar la Torah, saludar, llevar ropas recién lavadas, cortarse el cabello o presentarse en cualquier fiesta. A nosotros mismos nos extraño, recién llegados a Melilla ver a amigos nuestros hebreos desaseados, con la kipá por la calle - cuando normalmente no la llevaban-que no nos saludaban o lo hacían tímidamente con los ojos o con un ademán, cuando estaban de luto.

El luto de treinta días, Shloshim, es más benigno y fundamentalmente en los varones, consiste en no ir con ropas nuevas y no afeitarse ni cortarse el cabello una serie de prescripciones litúrgicas sinagogales.

El luto del año (Rosh), se circunscribe prácticamente a prescripciones litúrgicas.

Pero ante todo y sobre todo los judíos de Mclilla al igual que sus correligionarios del resto del mundo, tienen presente, como dice Joseph Caro, que el Señor es justo en todos sus actos y por eso está rigurosamente prohibido lamentarse en exceso por una muerte. Por ello hemos observado que el luto dura un mes y he aquí como el Hilulá es día de alegría y no de tristeza.

Somos conscientes que sólo hemos dado unas breves pinceladas en las variadas y numerosísimas constumbres religiosas judías, pero repetimos una vez más que cste era nuestro propósito y sobre todo ver la incidencia social de tales actos religiosos en el resto de la población, en especial cntre la cristiana que como hemos podido observar participaba en aquellas de carácter público o festivo con asiduidad y bencplácito; y nos llamaba atención cómo aprovechando una fiesta judías, la del Purim, moros y cristianos participaban de ella, no sólo invitándose en casa de los hebreos, sino participando activamente, en algo que les estaba prohibido a todos, pero que gracias a la benevolencia del Comandante General y a la costumbre social religiosa judía se permitía durante tres días; el juego del bacarrat, que hacía furor entre los melillenses de las tres religiones.

Acabaremos indicando que cualquier ficsta era buena para los judíos de alcurnia y algunos de modesta posición, para ejcrcer dos bonitas costumbres reliogas o Mitzvaim, una el Mishloay Manot: presentes a los amigos o correligionarios que tenga por lo menos dos productos comestibles; y, la otra: el Matanot Laevionim, regalos a los pobres en especies y en métalico. La sedaca, es decir la caridad es también una constante, activa y hermosa costumbre practicada generalmente de forma anónima por la sociedad judía melillense. 


\section{APÉNDICE I \\ RELACIÓN DE LOS JUDÍOS MELILLENSES ENTERRADOS EN EL VIEJO CEMENTERIO ISRAELITA DE SAN CARLOS (1883-1893)}

\author{
Fecha Libro $\mathrm{N}^{2}$
}

Nombre

$\begin{array}{rrrl}21-11-1883 & 4 & 51 & \text { Mimón Levy Benaim } \\ 7-8-1885 & 5 & 61 & \text { Esther Benmiara Benolille } \\ 5-8-1886 & 6 & 64 & \text { Moisés Chocrón Obadía } \\ 21-9-1886 & 6 & 78 & \text { Elisat Levy Bensien } \\ 31-12-1887 & 7 & 93 & \text { Jacob Aboab Bensih } \\ 17-6-1887 & 7 & 51 & \text { Elías Benolille Darmon } \\ 7-6-1887 & 7 & 45 & \text { David Benmiara Benolille } \\ 22-11-1887 & 7 & 87 & \text { Hainch Bitan Bennain } \\ 30-6-1887 & 7 & 59 & \text { Moses Bitan Bensadon } \\ 21-2-1887 & 7 & 10 & \text { Jacot Bitan Bitan } \\ 9-9-1987 & 7 & 74 & \text { Meshod Creciente } \\ 26-6-1887 & 7 & 54 & \text { Moises Chocrón Chocrón } \\ 30-6-1887 & 7 & 58 & \text { Freja Levy García } \\ 5-2-1887 & 7 & 7 & \text { Nain Jazon } \\ 2-2-1888 & 8 & 2 & \text { Jacob Aserraf } \\ 27-5-1888 & 8 & 37 & \text { Mcjanian Benmiara } \\ 28-12-1888 & 8 & 100 & \text { Isaac Chocrón Chocrón } \\ 14-12-1888 & 8 & 81 & \text { Simija Chocrón Chocrón } \\ 7-6-1888 & 8 & 39 & \text { Simi Mofada Benamir } \\ 31-12-1888 & 9 & 2 & \text { Brahan Benguigui Bahan } \\ 23-2-1889 & 9 & 26 & \text { Alegría Bemmiyara Saba } \\ 12-9-1889 & 9 & 85 & \text { Moisés Benaim Levy } \\ 15-9-1889 & 9 & 86 & \text { Abraham Benain Dian } \\ 13-10-1889 & 9 & 96 & \text { Ayuch Benolon Cohen } \\ 14-2-1889 & 9 & 23 & \text { Isaac Bitan Bitan } \\ 22-1-1889 & 9 & 10 & \text { Merian Bitan Bitan } \\ 18-1-1889 & 9 & 6 & \text { Mose Bitan Serfaty } \\ 21-5-1889 & 9 & 43 & \text { Sultana Corcia Corcia } \\ 1-1-1889 & 9 & 3 & \text { Hamed Chocrón Chocrón } \\ 4-2-1889 & 9 & 17 & \text { Isaac Chocrón Obadía } \\ 29-9-1889 & 9 & 90 & \text { Maja Chocrón Chocrón } \\ 1-10-1889 & 9 & 91 & \text { Camera Chocrón Chocrón } \\ 4-2-1889 & 9 & 16 & \text { Salomón Edila } \\ 26-8-1889 & 9 & 81 & \text { Abraham Levy Corcia } \\ 26-1-1889 & 9 & 12 & \text { Freja Levy Benaim } \\ 2-1-1889 & 10 & 9 & \text { Naftali Benguigui N. } \\ 11-7-1890 & 10 & 66 & \text { Marian Bitan Chocrón } \\ 5-10-1890 & 10 & 93 & \text { Elias Cohen Bennain } \\ 4-11-1890 & 10 & 6 & \text { Abraham Chocrón Chocrón } \\ 17-12-1890 & 10 & 15 & \text { Simija Chocrón Cohen } \\ & & & \end{array}$

Causa

Edad
Muerte natural 75

Gastroenteritis $\quad 7 \mathrm{~m}$.

Tétanos espontáneo $7 \mathrm{~d}$.

Fiebre viciosa 9

Crup 2

Tifus cerepro esp. $\quad 26 \mathrm{~m}$.

Pulmonía $18 \mathrm{~m}$.

Hemorragia cereb. $\quad 105$ años

Tisis gaseosa 8 años

Bronquitis Capil. 45 años

Asesinado en Beni-Bugafar

Tisis gaseosa

Neumonía aguda $\quad 18$ meses

Fiebre tifoidea

Ipletogia corazón 25 años

Gangrena testículo $\quad 70$ años

Viruela malina 5 años

Viruela malina 3 años

Fiebre consecutiva $\quad 45$ días

Viruela malina $\quad 6$ años

Raquitismo $3 \mathrm{~m}$.

Peritonitis 5 años

Meningitis cerebral 2 años

Raquitismo 9 días

Raquitismo 1 mes

Viruela Maligna 3 años

Viruela Maligna 1 año

Hemorragia Pucrperal

Viruela Maligna $\quad 7$ años

Virucla Maligna 5 meses

Derrame scroso

Congestión cerebral

Viruela maligna $\quad 3$ años

Raquitismo 3 meses

Viruela maligna 1 año

Tétanos Traumático $\quad 40$ años extirpación quiste.

Anasaria general

Bronquitis capilar $\quad 7$ días

Fiebres tifoideas

Congestión cerebral
10 años

6 meses 


\begin{tabular}{|c|c|c|c|c|c|c|}
\hline $29-1-1890$ & 10 & 30 & Moisés Chocrón Chocrón & Pulmonía aguda & 2 & años \\
\hline $2-12-1890$ & 10 & 8 & Luisa Didien Chocrón & Fiebre tifoidca & & \\
\hline $12-6-1890$ & 10 & 58 & David Dahan Dahan & $\begin{array}{l}\text { Hundimiento cueva Mante } \\
\text { (mayor de edad) }\end{array}$ & & \\
\hline $20-3-1890$ & 10 & 44 & Isaac Levy Benalit & - & 6 & días \\
\hline $10-2-1890$ & 10 & 34 & Cambra Sultán Chocrón & Bronquitis capilar & 4 & meses \\
\hline 19-11-1891 & 12 & 57 & Jacob Afugucros Jacsus & Derrame cerebral & 16 & años \\
\hline $5-2-1892$ & 12 & 85 & Efrain Arruaz Hachuel & Bronco-neumonía & 17 & meses \\
\hline $13-2-1892$ & 12 & 88 & Sadía Abuach Lankai & Pleuro-neumonía & 40 & años \\
\hline $22-2-1892$ & 12 & 93 & Luna Bendayan Carciente & Congestión pulmonar & 2 & años \\
\hline $20-9-1891$ & 12 & 40 & Joseph Chocrón Obadía & Gastroenteritis & 11 & meses \\
\hline $23-9-1891$ & 12 & 42 & Jacob Serfaty Elvas & Baquipcia Palúdica & 23 & años \\
\hline $28-3-1892$ & 13 & 8 & \multicolumn{2}{|c|}{ Guerson Benarroch Bensaquen Lesión cardíaca } & 30 & años \\
\hline $3-10-1892$ & 13 & 79 & David Bemmillara Benasuli & Nefritis parenquismática & 59 & años \\
\hline 23-10-1892 & 13 & 89 & Maimón Bennain Bendayan & Tumor abdominal & 10 & años \\
\hline $12-10-1892$ & 13 & 81 & Anisa Cohen Bensusan & Raquitismo & 4 & años \\
\hline $15-7-1892$ & 13 & 48 & Camera Chocrón Chocrón & Gastroenteritis & 2 & años \\
\hline $12-10-1892$ & 13 & 82 & Juda Levy Benhuali & Tubercolosis pulmonar & 18 & meses \\
\hline $31-8-1892$ & 13 & 65 & David Mileli Benamu & Disentería aguda & 50 & años \\
\hline $12-6-1892$ & 13 & 35 & Aarón Sultán Indo & Ulcera de estómago & 60 & años \\
\hline $30-12-1892$ & 13 & 101 & Jacob Trujman Corsia & Balbulo intestinal & 38 & años \\
\hline $1-7-1893$ & 14 & 47 & José Agnin Agnin & Nefritis & 38 & ã̃os \\
\hline $7-11-1893$ & 14 & 6 & Jacob Bitan Bitan & Meningitis rubcrculosa & 28 & días \\
\hline $1-7-1893$ & 14 & 53 & Anisa Bensaquen Doguis & anasarea General & 80 & años \\
\hline $1-8-1893$ & 14 & 60 & Ragel Benhamu Benhamu & Laringitis aguda & 4 & años \\
\hline $6-8-1893$ & 14 & 63 & Menhen Benhamu Califa & Fiebre Tifoidea & 31 & años \\
\hline $4-9-1893$ & 14 & 74 & Isaac Bcnamu Scsac & $\begin{array}{l}\text { Congestión cerebral } \\
\text { por golpe }\end{array}$ & 38 & años \\
\hline $4-9-1893$ & 14 & 75 & Moisés Benamu Elibas & Herida cabeza por golpe & 14 & años \\
\hline $4-9-1893$ & 14 & 72 & Joseph Levi Levi & Angina de pecho & 55 & años \\
\hline $1-12-1893$ & 15 & 61 & Moisés Benamu Draiza & Angina gangrenosa & 11 & arios \\
\hline $5-11-1893$ & 15 & 35 & Joar Bitan Dreye & Angina perenquimatosa & 6 & ã̃os \\
\hline $6-12-1893$ & 15 & 68 & Merian Benarroch Teoclen & $\begin{array}{l}\text { Bronco-ncumonía } \\
\text { sarampión }\end{array}$ & 2 & años \\
\hline $3-12-1893$ & 15 & 64 & Joseph Chocrón Sada & Falta de desarrollo & 1 & año \\
\hline $6-10-1893$ & 15 & 3 & Mercedes Levi Levi & Gastrocnteritis & 14 & meses \\
\hline
\end{tabular}

(1) Falleció en Beni-Bugafar, territorio próximo a Melilla. 
a) KETUBAH ORIGINAL

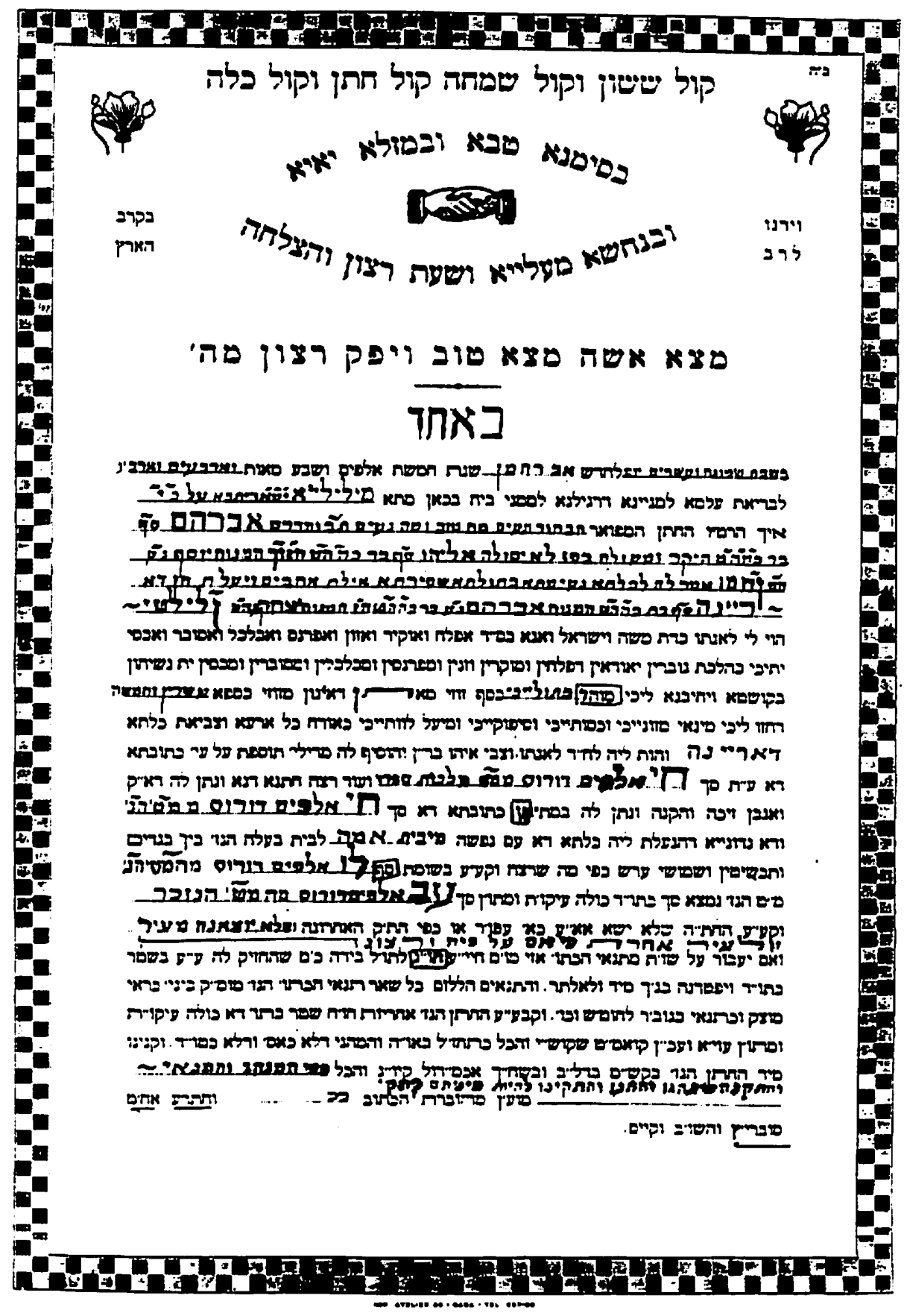




\section{B) TRADUCCIÓN ${ }^{1}$}

\section{VOZ DE GOZO Y VOZ DE ALEGRIA, VOZ DEL NOVIO Y VOZ DE LA NOVIA EN BUENA HORA Y CON DICHA COMPLETA Quien encuentra mujer halla bienestar y bencvolencia del Eterno}

Haga el Scñor que esta mujer que cntra en tu casa sca como Raquel y Lea, que edificaron la casa de Isracl.

Que por ella seas poderoso en Efratz y tengas renombre en Belén.

Que sca tu casa como la casa de Fares, el que Tamar dió a Judá, por la descendencia que de esta joven te dé Dios.

\section{EN}

el primer día de semana, correspondientc al $28 \mathrm{dcl}$ mcs de $\mathrm{AB}$, apodado cl piadoso, del año 5744 de la creación y ante la congregación aquí presente en la ciudad de Melilla (que El Eterno haga prosperar), he aquí el joven (nombre), hijo del señor (nombre), hijo a su vez del señor (nombre), dice a la encantadora moza, bella, y joven (nombre), hija del señor (nombre), hijo a su vcz de (nombre): vamos a cstablecer unión sagrada como la unión de Moisés y cl pucblo de Israel, y me comprometo D. M. a abastecerte, provecrte y facilitarte toda clase de biencstar social y económico, así como regalos, vestuarios, necesidades y caprichos, para convertirle en señora digna, a cuyo objeto me comprometo en la fienza de (cantidad) importe al que voluntariamente añado la cantidad de ..., importes pagaderos en moneda de curso legal del Rcino de España. Y aún se compromete el novio a concedcrle desinteresadamente y sin condición alguna todo el contenido de este cscrito (Ketubbá).

El concepto de abandono del hogar familiar para integrarse en su nuevo hogar cl novio ofrece a la novia la suma de (cantidad) duros cspañoles.

Asimismo cl referido novio sc compromete a no tomar por csposa a otra mujer, que no sea la mencionada en la presentc ketubbá, así como tampoco abandonarla ni marchar a otra ciudad distinta, sin previo consentimicnto de la novia.

Todos estos compromisos quedan atados por el presente contrato mantrimonial, como quedaron en su día los acuerdos fijados entre los descendientes de las tribus de Reuben y Gad.

Asimismo se responsabiliza cl novio de hacer patente cl respeto y cariño a la novia, por su partc y por otra parte de sus familiares (de él).

Queda patente la integración cconómica de la novia en todos los negocios, fincas y demás que realice y vaya a realizar cl novio.

Todos cstos apartados de acuerdo con la enseñanzas de nucstros sabios (q.c.p.d.).

Queda escriturado cl juramento del novio de cumplir cstas condiciones, guardarlas, haccrlas, practicarlas desde cl principio al fin.

(1) (Traducción realizada por León Benguigui Cohen) 
Y todo esto de acuerdo con las cnscñanzas, doctrinas, costumbres, modas, lcyes y normas que dictaron nucstros grandes rabinos (sobre cllos la paz), que habitaron en el Reino de Castilla. Suplicamos al Eterno la concesión de eterno descanso para sus almas y que su recuerdo permanezca imborrable en todos los confines de la tierra. Amen. El Escriba:

Firma:

Firma del Novio

Firma de testigos 